Rolińska Agnieszka. The organisational and psychosocial aspekts of adherence to diabetes therapy. Journal of Education, Health and Sport. 2020;10(8):150-156. eISSN 2391-8306. DOI http://dx.doi.org/10.12775/JEHS.2020.10.08.017

https://apcz.umk.pl/czasopisma/index.php/JEHS/article/view/JEHS.2020.10.08.017

https://zenodo.org/record/3974612

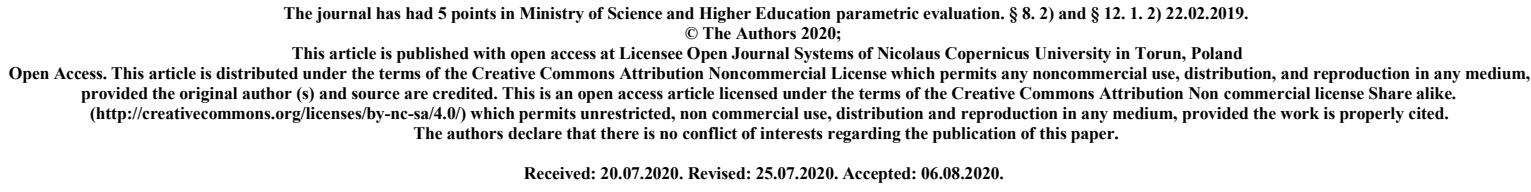

\title{
The organisational and psychosocial aspekts of adherence to diabetes therapy
}

\section{Rolińska Agnieszka}

Department of Applied Psychology

Medical University of Lublin

Chodżki 7, 20-093

Lublin, Poland

e-mail: agnieszka.rolinska@umlub.pl

ORCID: 0000-0001-5595-3077

\begin{abstract}
The global prevalence of diabetes is on the rise. The World Health Organization (WHO) estimates that diabetes will be the 7th leading cause of death in 2030. People with untreated or inadequately controlled diabetes are at greater risk of developing complications from SARSCoV-2 infection in the COVID-19 pandemic. Adapting to therapy for diabetes is a complex process. Numerous studies show the importance of many indirect, non-clinical factors in the treatment of patients with diabetes. It is necessary to develop methods that facilitate the selection of patients at risk of non-adherence to the disease due to psychological, organizational and/ or socio-demographic factors, including in the medical tele-counseling system currently intensively developing in diabetology.
\end{abstract}

Key words: diabetes, adherence, psychosocial, organisational factors 


\section{Introduction}

Adaptation to diabetes is defined the same as adaptation to chronic diseases in general. This term is translated to "active, voluntary, conscious and cooperative involvement of the patient in a mutually accepted course of activities aimed at bringing therapeutic results" [1]. In other words, it is "the degree to which the patient's behavior is consistent with the treatment recommendations" [2]. The patient internalizes the treatment recommendations and displays an attitude, behavior that is consistent and conducive to the agreed treatment plan (correct, positive adaptation) or inadequate, unfavorable to the treatment process. This usually applies to issues such as: proper medication intake, avoidance of stimulants and risky behavior, proper diet, physical activity, regular check-ups or self-control. It should be remembered that adaptation to disease is a complex concept. It is conditioned by many factors (socioeconomic, psychological, related to the specific therapy of a given disease, etc.). Moreover, a patient may achieve good treatment results in one of the assumed therapeutic conditions, e.g. concerning adherence to a diet, and may show neglect of another factor, e.g. glycemic selfcontrol [2].

\section{Adherence in the treatment of diabetes}

Patients with diabetes are "guided by" two main goals of therapy - striving to maintain the carbohydrate balance in the body and avoiding the occurrence, reducing the risk of diabetic complications. Health behaviors resulting from the recommendations in this disease include: self-monitoring of glucose levels (blood, urine) and maintenance of glucose levels within the range considered to be normoglycemia, maintaining an appropriate diet, weight reduction in obesity, taking oral hypoglycemic drugs, insulin therapy, regular undertaking physical activity and attending checkups, as well as possible other behaviors related to the development of diabetic complications (e.g. treatment of lipid disorders, arterial hypertension, caring for the condition of the oral cavity). These actions vary depending on the type and severity of diabetes with which the patient is struggling. It should be emphasized that among patients with chronic diseases, the group of diabetic patients is particularly exposed to problems related to inadequate adaptation to treatment [3-5]. The specificity of adaptation to diabetes is particularly influenced by the fact that it is a chronic disease - the process of adaptation to it is a continuous and long-term phenomenon. It requires comprehensive therapy from the patient making various changes, often perceived as limitations or a kind of compulsion, which cover many spheres of life. Research suggests that patients show a better attitude and motivation towards pharmacological therapy than towards introducing and continuing changes in their lifestyle (regular physical activity or adherence to a specific diet) [6, 7]. However, even in the treatment based on pharmacotherapy, patients often omit the doses of drugs, including as many as $1 / 3$ of diabetics patients taking drugs without following the pharmacotherapy model established by the doctor [8]. Proper adaptation to diabetes is often determined by various, not always "strictly clinical" factors. The literature on the subject describes numerous studies indicating the existence of a relationship between adaptation to this disease and the following variables: demographic, social, health care, and psychological. 


\section{Diabetes therapy and socio-demographic and organizational factors}

As shown by the data from the research, in terms of factors beyond psychological factors, certain socio-demographic factors are one of the conditions associated with worse adaptation to this disease. They include: low socioeconomic status, belonging to an ethnic minority or low level of education [9]. Lower socioeconomic status is associated with decreased diabetes knowledge and a decreased likelihood of using preventive health care services, which results in a higher need for specialized care [10]. Among other things, lower levels of glycemic selfcontrol among African-American and Mexican-American minorities with type I diabetes in the United States are observed [11]. The number of people with diabetes (especially type 2) in Africa is also constantly increasing [12]. Moreover, mortality rates are high because of it. Contributing to this are: late diagnosis, lack of education, inadequate access to insulin, antidiabetic drugs and devices supporting self-control of glycaemia, and to medical care. Moreover, it is worth adding that the following are typical for this geographical region: tropical diabetes associated with malnutrition, ketosis prone to atypical diabetes [12]. Lower level of education is indicated as independent factor associated with nonadherence to recommendations for blood glucose self-monitoring at least daily in patients with type 2 diabetes [13].

Another factor related to adaptation to diabetes is the quality of the patient's healthcare system. Apart from the obvious issues, such as experience and knowledge of medical personnel or the possibility of reimbursement of treatment costs, good organization of patient care in the time perspective is also important. Organizational variables may be conducive to strengthening the patient's motivation and memory regarding the content related to the therapy, e.g. in some hospitals in the United States, postcards or direct telephone contact with the patient in order to remind them not to report for a check-up [2]. Hee-Seung Kim and JeongAh Oh (2003) [14] conducted an interesting study based on the radomized design with the control and research group. They showed that nurse telephone intervention can improve $\mathrm{HbA1c}$, and diet and blood glucose testing adherence in patients with type 2 diabetes mellitus. The intervention (telephone's calls) was applied to the research group for 12 weeks, and consisted of continued education and reinforcement of diet, exercise, medication adjustment recommendations, as well as frequent self-monitoring of blood glucose levels. An effective solution to monitor the complications of the diabetes may also be telemedicine. Since the early 1990s to the end of 2019, a lots of telemedicine projects and studies have been developed in some countries in the field of diabetes and its management [15]. The system of e-prescriptions and tele-consultations used in many countries, including Poland, which was successfully introduced before the outbreak of the pandemic, works very well in diabetology, which made it easier for doctors to care for diabetic patients at the extremely difficult time. In addition, telemedicine are more convenient form of contact for patients, saving time needed to travel. According to systematic review by Lee JY, et al. (2018) the use of telemedicine for retinal screening (teleophthalmology) was not only beneficial but also one of the most costeffective interventions for diabetes management [16]. Nowadays, the struggle with diabetes is of course also facilitated by treatment facilities introduced over the years, including for example insulin pumps or new generations of insulin preparations characterized by a faster or longer duration of action, preventing postprandial hypoglycemia and hyperglycemia [17]. 
Modern technologies also help - continuous glucose monitoring systems allow not only to check the glucose level with a mobile phone, but also to send the measurement to the attending physician.

\section{Diabetes therapy and psychological factors}

Despite the significant facilities that developed the treatment of diabetes today and taking into account a properly established treatment plan, there are patients who do not comply with the doctors' orders. This tendency is well illustrated by a survey which was conducted in the United States in the representative sample of 1,480 subjects with type 2 diabetes [18]. Results showed that: $24 \%$ of patients with insulin therapy, $65 \%$ treated with orally administered drugs, and $80 \%$ only on diet and recommendations of physical activity have never or no more than once a month performed at least one blood glucose test per day. Only 39\% of patients treated with insulin measured glucose at least once a day, and only $5 \%$ of patients treated with other treatments [18]. In another study conducted in 2005, in a large sample of 5,104 patients with type 1 diabetes and 3,827 patients with type 2 diabetes, the following results were obtainedpresenting the number of patients with adequate adaptation to the disease depending on the type of diabetes they have: $83 \%$ and $78 \%$ for the use of drugs, $70 \%$ and $64 \%$ for the daily glucose measurement, $39 \%$ and $37 \%$ for compliance with the dietary regimen, 71 and $72 \%$ for regular visits to the doctor and $37 \%$ and $35 \%$ for physical exercise [19]. In one study conducted in Poland, patients who assessed themselves as adhering to therapeutic recommendations did not have, ,well-balanced" diabetes [20].

The above data make it clear that the treatment of diabetes can, to a large extent, be inappropriate "through the fault" of the patients themselves. This state of affairs is significantly influenced by psychological factors related to the treatment of patients with diabetes. Often in an indirect, but essential way, they determine the positive course of the therapy process, influencing the patient's attitude towards their disease, motivation for treatment and health behaviors manifested by the patient. It must not be forgotten that the treatment of diabetes is primarily based on the active role of the patient. Therefore, the motivation and attitude shown by the patient himself towards his or her health condition and the treatment process, as well as taking into account subjective, psychological aspects that may disturb the therapies are extremely important. Even if ideal conditions for treatment were created for the patient, they would not bring the expected results, if at the psychological level the patient manifested various mental and cognitive barriers that are not appropriate for therapy.

Depression is also a serious threat to the adequate treatment process in diabetes. Research suggests that co-morbidity of diabetes and depression is often [21]. The relationship between this disease and worse adaptation to treatment of patients with diabetes has been confirmed in many studies. Gonzalez J. et al. (2008) reviewed the literature covering data from 1950-2008 (Medline, PsychInfo) confirming the significance of the above relation [22]. The same conclusion was reached by Egede L. et al. (2010) based on a literature review from 1966-2009 (Medline). Moreover, it confirmed that the occurrence of depression in people with diabetes correlates with higher mortality and the number of diabetic complications [23]. Lin. E. et al. noted a correlation between struggling with depression and weaker physical activity, omitting doses of hypoglycemic drugs and inaccurate dietary adherence in a group of 
4,463 patients [24], while Richardson L. in a longitudinal study involving a large group of 11,525 elderly patients showed a correlation between the state of depression and incorrect results in terms of glycated hemoglobin [25]. In order to assess depression in patients with diabetes, Kokoszka (2008) developed standard norms in the representative sample for this population [26]. As a result, the Short Self-Assessment Depression and Anxiety Scale is recommended as a screening tool in everyday practice with diabetic patients. Apart from depression, also dealing with psychotic and eating disorders is also dangerous for patients with diabetes [27-29].

Another factor that worsen adaptation to diabetes mentioned in the literature is a distorted subjective picture of one's own disease, also referred to as the cognitive representation of the disease [30]. Studies have confirmed that it is associated with appropriate or inappropriate adaptation to treatment in patients with type I and type II diabetes [31-33]. For example: Broadbent E. et al. (2011) among 108 patients with type 2 diabetes and 49 patients with type 1 diabetes, noted a significant correlation between the patient's perceived personal control over the environment and glycemic control [7]. The stronger the sense of control manifested by the patients, the better was their glycemic control [7]. On the other hand, other researchers showed a significant correlation between the beliefs about the effectiveness of the therapy and the perceived seriousness of the disease, and compliance with the diet by patients $[34,35]$.

Diabetes education of patients with diabetes should also take into account the assessment of the current mental state and motivation, which may be variable. Swanson V., et al. (2019) in their review discuss how motivation is related to diabetes self-management [36]. Identifying periods of lower adherence and strengthening patients' motivation is important to maintain optimal treatment outcomes.

\section{Summary}

Studies present that patients with diabetes have worse adaptation to medical recommendations when they include changes in the current lifestyle (e.g. diet), and better when they concern on taking medications [37]. Not only the type of diabetes -which the patient is affecteddetermining the specific factors related to the treatment method, is significant in adherence to long-term disease. Numerous data indicate the importance of psychological, organizational and socio-demographic factors in the treatment of diabetes. Their knowledge and assessment by clinicians is particularly important in the time of the Covid-19 pandemic, when the socalled the patient-centered approach in medicine faces many difficulties.

\section{Bibliography}

1. Meichenbaum D, Turk DC: Facilitating Treatment Adherence: A Practitioner's Guidebook. New York, Plenum Press, 1987.

2. Haynes BR, Taylor DW, Sackett DL (edits.): Compliance in health care. Baltimore MD: The Johns Hopkins University Press, 1979.

3. King H, Aubert RE, Herman WH: Global burden of diabetes 1995-2025: Prevalence, numerical estimates and projections. Diabetes Care, 1998, 21.

4. Beckles GL (et al.): Population-based assessment of the level of care among adults with diabetes in the U.S. Diabetes Care, 1998, 21. 
5. Dunbar-Jacob J (et al.): Adherence in chronic disease. Annual Review of Nursing Research, 2000, 18.

6. Anderson RM, Fitzgerald JT, Oh MS: The relationship of diabetes-related attitudes and patients' self-reported adherence. Diabetes Educ. 1999, 19.

7. Boadbent E, Donkin L, Stroh J: Illness and Treatment Perceptions Are Associated With Adherence to Medications, Diet, and Exercise in Diabetic Patients. Diabetes Care, 2011, $34(2)$.

8. Kowalczyk E: Rusza Kampania Społeczna: Cukrzyca bez powikłań. Kurier Medycyny, 2015. Źródło: Rynek Zdrowia/cukrzycabezpowiklan.pl.

9. Delamater AM, Jacobson AM, Anderson BJ, Cox D, Fisher L, Lustman P, Rubin R, Wysocki T: Psychosocial therapies in diabetes: report of the Psychosocial Therapies Working Group. Diabetes Care, 2001, 24.

10. Zgibor JC, Songer TJ: External barriers to diabetes care: addressing personal and health systems issues. Diabetes Spectrum, 2001, 14(1), 23-28.

11. Harris MI, Cowie CC, Howie LJ: Self-monitoring of blood glucose by adults with diabetes in the United States population. Diabetes Care, 1993,16.

12. Jaffiol C: The burden of diabetes in Africa: a major public health problem. Bull Acad Natl Med., 195(6).

13. Karter AJ, Ferrara A, Darbinian JA, Ackerson LA, Selby JV: Self-monitoring of blood glucose: language and financial barriers in a managed care population with diabetes. Diabetes Care, 2000, 23, 477-483.

14. Kim HS, Oh J: Adherence to diabetes control recommendations: impact of nurse telephone calls. J Adv Nurs., 2003, 44(3):256-61.

15. Andrès E, Meyer L, Zulfiqar A-A, Hajjam M, Talha S, Bahougne T, Ervé S, Hajjam J, Doucet J, Jeandidier N, El Hassani A H: Telemonitoring in diabetes: evolution of concepts and technologies, with a focus on results of the more recent studies. Journal of Medicine and Life, 2019, 12, 3.

16. Lee JY, Lee SWH: Telemedicine cost-effectiveness for diabetes management: a systematic review. Diabetes Technol Ther. 2018, 20:492-500.

17. Singh S, Ahmad F, Lal A, Yu C, Bai Z, Bennet H: Efficacy and safety of insulin analogues for the management of diabetes mellitus: a meta-analysis. Canadian Medical Association Journal, 2009, 180.

18. Harris MI: Frequency of blood glucose monitoring in relation to glycemic control in patients with type 2 diabetes. Diabetes Care, 2001,24.

19. Peyrot M, Rubin RR, Lauritzen T, Snoek FJ, Matthews DR, Skovlund SE: Psychosocial problems and barriers to improved diabetes management: results of the CrossNational Diabetes Attitudes, Wishes and Needs (DAWN) Study. Diabet Med, 2005, 22.

20. Matej-Butrym A, Butrym M, Jaroszyński A: Samoocena przestrzegania zaleceń lekarskich a gospodarka węglowodanowa u chorych na cukrzycę typu 2. Family Medicine \& Primary Care Review, 2015, 17(2): 111-114.

21. Roy T, Lloyd CE: Epidemiology of depression and diabetes: A systematic review. Journal of Affective Disorders, Suppl. 2012, 142.

22. Gonzalez J, Peyrot M, McCarl L (et.al.): Depression and Diabetes Treatment Nonadherence: A Meta-Analysis. Diabetes Care, 2008, 31(12). 
23. Egede L, Ellis Ch: Diabetes and Depression: Global Perspectives. Diabetes Res Clin Pract., 2010, 87(3).

24. Lin E, Katon W, Von Kroff M (et al.): Relationship of depression and diabetes selfcare, medication adherence, and preventive care. Diabetes Care, 2004, 27 (9).

25. Richardson L, Egede L, Mueller M, Echols C, Gebregziabher M: Longitudinal effects of depression on glycemic control in veterans with Type 2 diabetes. Gen. Hosp. Psychiatry, 2008, 30(6).

26. Kokoszka A: Krótka Skala Samooceny Depresji i Lęku: opis konstrukcji oraz właściwości psychometryczne dla osób z cukrzycą. Przew Lek, 2008, 6: 74-81.

27. Daneman D, Olmsted M, Rydall A, Maharaj S, Rodin G: Eating disorders in young women with type 1 diabetes. Prevalence, problems and prevention. Horm Res., 1998, 50.

28. Peet M: Diet, diabetes and schizophrenia: review and hypothesis. Br J Psychiatry, Suppl. 2004, 47.

29. Delamater AM, Jacobson AM, Anderson BJ (et al.): Psychosocial therapies in diabetes: report of the Psychosocial Therapies Working Group. Diabetes Care, 2001, 24.

30. Brownlee-Duffeck M, Peterson L, Simonds JF, Goldstein D, Kilo C, Hoette S: The role of health beliefs in the regimen adherence and metabolic control of adolescents and adults with diabetes mellitus. J Consult Clin Psychol, 1987, 55.

31. Nam S, Chesla C, Stotts NA, Kroon L, Janson SL: Barriers to diabetes management: Patient and provider factors. Diabetes Res Clin Pract., 2011, 93(1).

32. Harris R, Linn MW: Health beliefs, compliance, and control of diabetes mellitus. South Med J., 1985, 78.

33. Mirotznik J, Ginzler E, Zagon G, Baptiste A: Using the health belief model to explain clinic appointment-keeping for the management of a chronic disease condition. J Community Health, 1998, 23.

34. Hampson SE, Glasgow RE, Toobert DJ.: Personal models of diabetes and their relations to self-care activities. Health Psychol, 1990, 9.

35. Skinner TC, Hampson SE, Fife-Schaw C: Personality, personal model beliefs and selfcare in adolescents and young adults with type 1 diabetes. Health Psychol, 2002, 21.

36. Swanson V, Maltinsky W: Motivational and behaviour change approaches for improving diabetes management. Practical Diabetes, 2019, 36, 4.

37. Ary DV, Toobert D, Wilson W, Glasgow RE: Patient perspective on factors contributing to non-adherence to diabetes regimen. Diabetes Care, 1986, 9. 